\title{
Effects of Mindfulness Meditation on Conscious and Non-Conscious Components of the Mind
}

\author{
Anastasia Fabbro ${ }^{1,5, *}$, Cristiano Crescentini ${ }^{2}$, Alessio Matiz ${ }^{3}$, Andrea Clarici ${ }^{4}$ and \\ Franco Fabbro 5 \\ 1 Department of Psychology, University of Rome La Sapienza, 00185 Rome, Italy \\ 2 Department of Languages and Literatures, Communication, Education and Society, University of Udine, \\ 33100 Udine, Italy; cristiano.crescentini@uniud.it \\ 3 Perceptual Robotics (PERCRO) Laboratory, Scuola Superiore Sant'Anna, 56010 Pisa, Italy; \\ alessio.matiz@santannapisa.it \\ 4 Psychiatric Clinic, Department of Medical, Surgical and Health Sciences, University of Trieste, \\ 34149 Trieste, Italy; clarici@units.it \\ 5 Department of Medicine, University of Udine, 33100 Udine, Italy; franco.fabbro@uniud.it \\ * Correspondence: anastasia.fabbro@uniroma1.it
}

Academic Editor: Peter Walla

Received: 31 January 2017; Accepted: 30 March 2017; Published: 1 April 2017

\begin{abstract}
The aim of the present review is to investigate previous studies concerning the effects of meditation and dispositional mindfulness on conscious and implicit or non-conscious attitudes. First we present a brief perspective on conscious and non-conscious states of mind. Then we introduce the fundamental bases of mindfulness meditation. Third we review studies on dispositional mindfulness and meditation that employed either direct or indirect measures to assess explicit and implicit attitudes. Finally, we briefly present how meditation has been associated with the psychotherapeutic practice of psychoanalysis and, hence, as a therapeutic technique to access the unconscious. Until now, few studies have investigated the impact of meditation on non-conscious states of mind and personality; nevertheless, both scientific studies involving implicit measures and reflections from psychotherapy have underlined the importance of meditation in promoting psychological well-being, leading to de-automatization of automatic patterns of responding and to higher levels of self-awareness.
\end{abstract}

Keywords: mindfulness; meditation; consciousness; unconscious; implicit attitudes

\section{Consciousness and Non-Conscious States}

Consciousness is probably one of the greatest and most fascinating mysteries of human nature; addressing this dimension means exploring a very complex and multifaceted topic. Developing our reflections about mindfulness and conscious states of mind, we have found a valid model for the understanding of consciousness in Tulving [1], who related consciousness to memory. Tulving has argued that different types of memory are related to different varieties of consciousness. He has described three types of memory. Semantic and episodic memory are explicit (or declarative) memories, that is to say, they refer to conscious experiences and to the acquisition of propositional, representable information [2]. While episodic memory concerns the recollection of personal past experiences, semantic memory has to do with the knowledge individuals have about the world, and does not imply a personal involvement. The third type of memory is the implicit (procedural) memory, which may not require consciousness and is non-propositional [2]. According to Tulving [1], these three memory systems distinguish themselves by different levels of consciousness; episodic memory is an example of 
autonoetic consciousness, semantic memory reflects noetic consciousness, and implicit memory includes non-conscious or anoetic states.

LeDoux [3] has described the autonoetic state as a sort of metacognitive awareness, or a type of higher-order awareness, a thought on ourselves. According to higher-order theories, a conscious state is a mental state which the individual is aware of [4]; a thought is consciously experienced when it is the object of another thought. While autonoetic consciousness concerns self-knowing and self-awareness, the noetic state is referred to as knowing; it is experienced when individuals think about something they know. Unlike the autonoetic states, we could consider noetic states as non-conscious states that, nevertheless, can come under the focus of awareness. Finally, individuals in an anoetic state are not aware of the state itself, and they do not have a phenomenic experience of it [3]; anoetic states are related to implicit memories, which do not require consciousness, are automatic, and never come under the focus of awareness.

In addition to these three types of consciousness (the autonoetic, noetic, and anoetic states), we mention also the Freudian unconscious; in this case, events that have been experienced in an autonoetic state have been actively distorted (through a series of defense mechanisms) as, for instance, in repression (whereas a representational content is removed from consciousness) [5]. Nevertheless, they can also flow into consciousness, through psychotherapeutic practices, or, for example, during dreams.

\section{Mindfulness Meditation: Origins and Practice}

The words "meditation" and "medicine" both come from the Latin verb medeor, which means "to cure", "to heal". Meditation, indeed, is practiced in order to cure physical, psychological, and spiritual suffering, and even if it was originally introduced within the spiritual traditions of the East, in the last decades it has been increasingly employed in psychological and medical contexts.

Mindfulness meditation was developed by Siddartha Gautama, known as the Buddha, over 2500 years ago [6]. The Buddha himself described a way to achieve the liberation from suffering, developed in eight steps (Noble Eightfold Path): right understanding, right intention, right speech, right action, right way of life, right effort, right mindfulness, and right unitive concentration [7]. In this perspective, mindfulness meditation is the seventh step that leads to the liberation from suffering; the Buddha himself taught how to practice mindfulness meditation in "The Great Discourse on the Foundations of Mindfulness". Here, he showed how to contemplate the nature of the body, focusing on awareness of breathing and awareness of body, and practicing the observation of the mind [8]. He also specified that the meditative practices needed for the seventh step of the Noble Eightfold Path concern the awareness of breath (anapanasati), body contemplation and the clear seeing of the mind (vipassanā). Vipassan $\bar{a}$ meditation in the last decades has been introduced in the medical and psychological fields by some researchers as a beneficial practice $[9,10]$. One of these researchers, Jon Kabat-Zinn, has developed and standardized a program of mindfulness meditation called mindfulness-based stress reduction (MBSR) [11,12]. The program involves eight weekly sessions that comprehend the description of theoretical concepts, meditative practice, hatha yoga exercises, and a space for discussion. This practice has shown to be useful in the treatment of organic and psychological diseases also leading to several neurobiological changes [13-16].

Mindfulness meditation is not a relaxation technique; indeed, it is a very difficult practice: it requires practitioners to stay seated and not to move, trying to focus their attention on the breath, the body, or on the mind. Naturally, the mind pays attention for a while, and then starts to wander in thoughts and fantasies; when people become aware that they are not focused on the task, they try to focus again on it without judging as positive or negative their distractions (non-judgmental attitude) [17,18]. This mindful disposition brings practitioners to cultivate a kind attitude towards themselves, and to recognize and accept mistakes. Another central topic of mindfulness is "dis-identification"; paying attention to body and breathing, from a certain "distance", can bring people to adopt a detached attitude toward the objects and the contents of their mind (emotions, thoughts, etc.) that they are paying attention to. Practitioners finally develop a sense of equanimity without being absorbed into 
their own mental processes; namely, they realize that the mental phenomena observed-thoughts, emotions, feelings-are distinct from the mind observing them $[19,20]$. Mindfulness is also aimed to achieve "de-automatization"; improving awareness and attention towards things that occur in the present, it brings people to behave in a more controlled and conscious manner. Finally, another important dimension of mindfulness concerns the experience of pain; the attitude of meditation suggests to simply stand in front of suffering, observing what is happening in our mind, being aware of all the sensations of pain, without reacting or running away [21]. At this point, it becomes possible to see and accept the present moment for what it is.

\section{Meditation and Explicit Self-Representations}

Our research group has focused its studies on mindfulness meditation and its effects on people's personality traits and psychological well-being. Campanella et al. [22] assessed the effects of a mindfulness-oriented meditation (MOM) training on individuals' personality by using the Temperament and Character Inventory (TCI) [23], a well-known personality inventory that allows to analyze two components of personality: temperament and character. Temperament is described as a system of automatic responses to the environment (four temperamental traits have been defined: novelty seeking, persistence, reward dependency, and harm avoidance). Character consists of three aspects that reveal the maturity of the self at the intrapersonal (self-directedness; it concerns concepts like self-efficacy and self-esteem), interpersonal (cooperativeness; it refers to traits such as empathy, compassion, and tolerance), and transpersonal (self-transcendence; the dimensions of spirituality and creativity) levels. A significant increase of the TCI aspects that measure the maturity of the self has been found in those participants who meditated regularly for two months. Effects of a MOM training have been investigated also in a clinical study with a group of patients with alcohol dependence; after two months of MOM training, subjects revealed increased maturity of the self [24].

These studies suggest that mindfulness meditation promotes positive changes in individuals' personality, but what does it mean? Since it is a self-report questionnaire, the TCI assesses people's personality at an explicit level: it reveals what people consciously think about themselves, their beliefs about how they are. Changes in TCI traits do not necessarily reveal changes in people's implicit personality aspects, but rather modifications in their explicit self-representations. These representations may, thus, refer to autonoetic and noetic states of consciousness.

\section{Meditation, Implicit Attitudes, and Implicit Memory}

We have briefly presented the TCI, an instrument that allows one to catch explicit self-concepts and attitudes about personality. Nevertheless, research and theory recognize two types of attitude: explicit and implicit. Explicit attitudes rely on propositional processes, and are shaped by well-articulated beliefs and motivations; implicit attitudes rely on automatic and associative processes, and are shaped by intuitive feelings and evaluations, that one could or could not be aware of [25]. From a methodological point of view, if explicit attitudes are measured directly with self-report questionnaires and scales, implicit attitudes are assessed indirectly with performance-based procedures, such as the popular Implicit Association Test (IAT) [26], which do not require self-reflection and avoid the direct influence of self-evaluation. In particular, the IAT is a computer test that requires participants to associate as fast as possible two target concepts to an attribute. The idea underlying this measure is that the more a concept and an attitude are implicitly associated in memory, the easier and faster participants associate them in the computer task (see Figure 1 for an example of stimulus sequence in a typical IAT experiment). 


\section{Example of Self-Esteem-IAT}

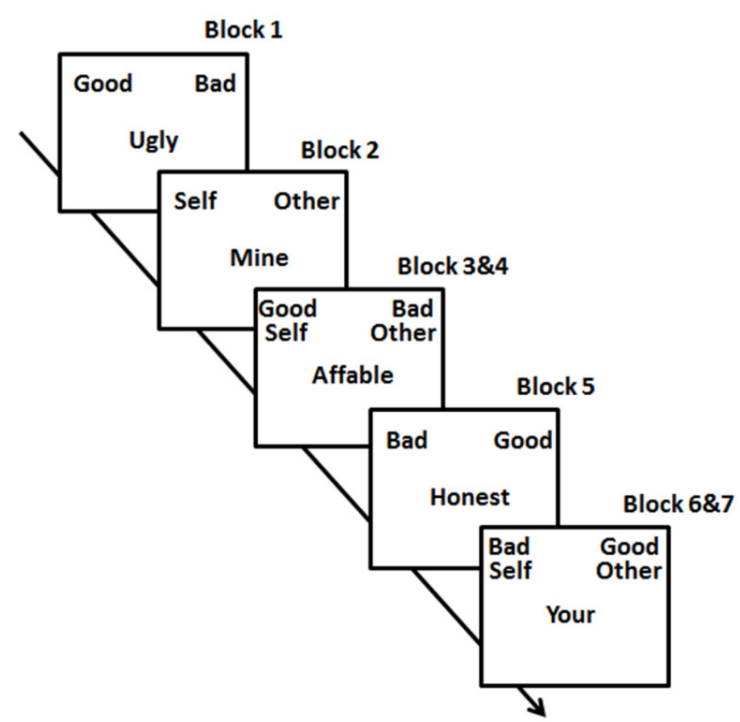

Figure 1. The schematic structure of a self-esteem IAT is reported. The IAT typically consists of seven blocks of trials (each block typically includes from 20 to 60 trials; blocks 1, 2, and 5 are familiarization blocks, while blocks 3 and 4 and blocks 6 and 7 are the congruent and incongruent blocks, respectively) in which a series of stimulus words appear at the center of the computer screen one at a time and must be associated to the stimulus categories (good, bad, self, other) shown on the upper left or right corner of the screen by pressing two corresponding response keys (e.g., in the first block good and bad words are presented one at a time, e.g., the bad stimulus word 'ugly' in the example, and have to be classified as being either good (left key) or bad (right key); the right key response is the correct response in the example). The IAT measures the strength of automatic concept-attribute associations. In the example of a self-esteem IAT this occurs between two groups of target words concerning the concepts of self vs. other and words related to good vs. bad dimensions (i.e., positive vs. negative valence words, respectively). The association is tested in both congruent (self + good; other + bad) and incongruent (self + bad; other + good) conditions. A self-esteem IAT effect is reflected by better performance (shorter response times and/or higher rate of correct response) in congruent than incongruent conditions, and indicates that a person automatically (implicitly) associates the self with positive rather than with negative valence (see $[27,28]$ for further details on the IAT and on the list of stimulus words that can be used for a self-esteem IAT).

It has been shown that explicit and implicit attitudes are not always coherent; moreover, incongruities between explicit an implicit self-representations are often related to several forms of psychological suffering [29,30]; concordance between explicit and implicit self-attitudes seem to be important for psychological well-being. In this perspective, studies have investigated which factors can contribute in some way to create a more coherent self-image, promoting a concordance between implicit and explicit representations; mindfulness has been seen as a useful construct in this direction.

While most of the research concerning the psychological effects of mindfulness meditation has assessed people's self-attitudes at an explicit level, few researchers have tried to understand if and how dispositional mindfulness (individuals' propensity for mindfulness) and/or meditative practice can affect implicit constructs, employing indirect measures to assess changes in implicit attitudes, prejudice, and stereotypes [31], but also addressing implicit self-esteem and self-concepts (see [32]).

Some studies focused on the effects of meditation (and also dispositional mindfulness) on explicit and implicit attitudes, highlighting how mindfulness is correlated to an improved concordance between these two levels (see Table 1). 
Table 1. Empirical studies of effects of dispositional mindfulness and meditation on implicit and explicit measures.

\begin{tabular}{|c|c|c|c|c|c|c|c|c|c|}
\hline Ref. & Study & $\mathbf{N}$ & Meditation & $\begin{array}{l}\text { State/Trait } \\
\text { Mfn }\end{array}$ & Explicit Measure & Instrument & Implicit Measure & Instrument & $\begin{array}{ll}\text { Result } \\
\end{array}$ \\
\hline [33] & $\begin{array}{l}\text { Brown and Ryan } \\
\text { (2003)-study } 3\end{array}$ & 90 & - & $\mathrm{T}$ & trait mindfulness, affective state & $\begin{array}{l}\text { MAAS, Diener and } \\
\text { Emmons scale adapted }\end{array}$ & affective state & IAT & $\begin{array}{l}\text { higher mindfulness predicted } \\
\text { concordance between implicit and explicit } \\
\text { affective experience }\end{array}$ \\
\hline [34] & Sauer et al. (2011) & 247 & - & $\mathrm{T}$ & $\begin{array}{l}\text { trait mindfulness, mental } \\
\text { distress, emotional behavior }\end{array}$ & $\begin{array}{l}\text { FMI, BDI, STAI, } \\
\text { word/picture rating }\end{array}$ & $\begin{array}{l}\text { susceptibility to } \\
\text { evaluative conditioning, } \\
\text { emotional behavior }\end{array}$ & $\begin{array}{l}\text { evaluative } \\
\text { conditioning, } \\
\text { emotional Stroop } \\
\text { test }\end{array}$ & $\begin{array}{l}\text { "partial support that acceptance facet of } \\
\text { mindfulness may be associated with less } \\
\text { aversive reactions towards aversive } \\
\text { stimuli" (explicitly measured) }\end{array}$ \\
\hline [35] & Koole et al. (2009) & $\begin{array}{l}130 \text { (study 1), } \\
58 \text { (study 2) }\end{array}$ & $\begin{array}{l}\text { MM } \\
\text { (body scan) }\end{array}$ & S & self-esteem, mood & $\begin{array}{l}\text { RSES (study 1), modified } \\
\text { RSES (study 2), POMS }\end{array}$ & self-esteem & name-letter task & $\begin{array}{l}\text { brief MM exercises increased association } \\
\text { between implicit and explicit self-esteem }\end{array}$ \\
\hline [36] & Keng et al. (2016) & 79 & $\begin{array}{l}\mathrm{MBCT} \\
\text { adaptation }\end{array}$ & $\mathrm{S}, \mathrm{T}$ & $\begin{array}{l}\text { trait mindfulness, dysfunctional } \\
\text { attitudes, depressive symptoms, } \\
\text { social desirability, sad mood, } \\
\text { perceived training efficacy, } \\
\text { training adherence, engagement } \\
\text { in rumination and distraction }\end{array}$ & $\begin{array}{l}\text { FFMQ, DAS-SF1, } \\
\text { BDI, SDS*,VAS, } \\
\text { check questionnaire, } \\
\text { Likert scale }\end{array}$ & dysfunctional attitudes & IAT & $\begin{array}{l}\text { "brief mindful acceptance training } \\
\text { improved implicit dysfunctional attitudes } \\
\text { among individuals with high trait } \\
\text { mindfulness" and promoted "greater } \\
\text { self-concordance between implicit and } \\
\text { explicit dysfunctional attitudes" }\end{array}$ \\
\hline [37] & $\begin{array}{l}\text { Crescentini et al. } \\
\text { (2014) }\end{array}$ & 29 & $\begin{array}{l}\text { MM (breath, } \\
\text { body, } \\
\text { thoughts) }\end{array}$ & $\mathrm{T}$ & $\begin{array}{l}\text { trait mindfulness, } \\
\text { religiousness/spirituality }\end{array}$ & FFMQ, TCI, INSPIRIT & $\begin{array}{l}\text { self-esteem, } \\
\text { religiousness/spirituality }\end{array}$ & IAT & $\begin{array}{l}\text { "MM training promoted congruent } \\
\text { increases in implicit and explicit } \\
\text { religiousness/spirituality" }\end{array}$ \\
\hline [38] & $\begin{array}{l}\text { Remmers et al. } \\
\text { (2016) }\end{array}$ & 72 & MM & $\mathrm{s}$ & trait mindfulness, mood changes & KIMS, PANAS & mood changes & IPANAT & $\begin{array}{l}\text { "short MM exercise induced } \\
\text { down-regulation of negative mood, } \\
\text { on both explicit and implicit levels" }\end{array}$ \\
\hline [39] & $\begin{array}{l}\text { Levesque } \\
\text { and Brown } \\
\text { (2007)—study } 2\end{array}$ & 78 & - & $\mathrm{T}$ & $\begin{array}{l}\text { trait mindfulness, dispositional } \\
\text { autonomy, day-to-day } \\
\text { motivation for behavior, } \\
\text { reflexive awareness }\end{array}$ & $\begin{array}{l}\text { MAAS, subscale of } \\
\text { SDS **, adaptation of } \\
\text { PLOC, portion of SCS, } \\
\text { subscale of RRQ }\end{array}$ & dispositional autonomy & IAT & $\begin{array}{l}\text { "mindfulness moderated the effect of } \\
\text { implicit motivational dispositions on } \\
\text { day-to-day motivation for behavior" }\end{array}$ \\
\hline [40] & $\begin{array}{l}\text { Waters et al. } \\
(2009)\end{array}$ & 158 & - & $\mathrm{T}$ & $\begin{array}{l}\text { trait mindfulness, depressive } \\
\text { symptoms, affect, stress } \\
\text { symptoms }\end{array}$ & $\begin{array}{l}\text { MAAS, KIMS, CESD, } \\
\text { PANAS, PSS }\end{array}$ & $\begin{array}{l}\text { self-association to } \\
\text { depression, to anxiety, } \\
\text { to smoke, attention }\end{array}$ & $\begin{array}{l}\text { IAT, modified } \\
\text { Stroop task }\end{array}$ & $\begin{array}{l}\text { "degree of mindfulness negatively } \\
\text { associated with implicit self-identification } \\
\text { with depression" }\end{array}$ \\
\hline [41] & $\begin{array}{l}\text { Hutcherson et al. } \\
\text { (2008) }\end{array}$ & 93 & LKM & $\mathrm{s}$ & $\begin{array}{l}\text { evaluations of photos } \\
\text { (self, a close other, } 3 \text { neutral } \\
\text { strangers), changes in affect }\end{array}$ & $\begin{array}{l}\text { Likert scale, } \\
\text { single question }\end{array}$ & $\begin{array}{l}\text { evaluations of photos } \\
\text { (self, a close other, } \\
3 \text { neutral strangers) }\end{array}$ & $\begin{array}{l}\text { affective priming } \\
\text { task }\end{array}$ & $\begin{array}{l}\text { brief LKM exercises caused higher explicit } \\
\text { and implicit feelings of positivity toward } \\
\text { strangers, and changes in implicit } \\
\text { positivity toward the self }\end{array}$ \\
\hline
\end{tabular}


Table 1. Cont.

\begin{tabular}{|c|c|c|c|c|c|c|c|c|c|}
\hline Ref. & Study & $\mathbf{N}$ & Meditation & $\begin{array}{l}\text { State/Trait } \\
\text { Mfn }\end{array}$ & Explicit Measure & Instrument & Implicit Measure & Instrument & Result \\
\hline [42] & Kang et al. (2013) & 101 & LKM & $\mathrm{T}$ & $\begin{array}{l}\text { cognitive control, } \\
\text { psychological stress }\end{array}$ & MSIT, PSS & $\begin{array}{l}\text { bias toward blacks and } \\
\text { homeless }\end{array}$ & IAT & $\begin{array}{l}\text { LKM training reduced implicit bias } \\
\text { toward blacks and homeless }\end{array}$ \\
\hline [43] & $\begin{array}{l}\text { Stell and } \\
\text { Farsides (2016) }\end{array}$ & 69 & LKM & $\mathrm{s}$ & positive emotions & mDES & racial bias & IAT & $\begin{array}{l}\text { short LKM exercises reduced implicit bias } \\
\text { on racial group targeted by exercises }\end{array}$ \\
\hline [44] & $\begin{array}{l}\text { Lueke and } \\
\text { Gibson (2014) }\end{array}$ & 72 & $\begin{array}{l}\text { MM } \\
\text { (heartbeat, } \\
\text { breath) }\end{array}$ & $\mathrm{s}$ & state mindfulness & $\begin{array}{l}\text { modified item } \\
\text { from MAAS }\end{array}$ & age and racial bias & IAT & $\begin{array}{l}\text { short MM practice decreased implicit race } \\
\text { and age bias }\end{array}$ \\
\hline [45] & $\begin{array}{l}\text { Lueke and } \\
\text { Gibson (2016) }\end{array}$ & 93 & $\begin{array}{l}\text { MM } \\
\text { (heartbeat, } \\
\text { breath) }\end{array}$ & S & $\begin{array}{l}\text { trait mindfulness, state } \\
\text { mindfulness }\end{array}$ & $\begin{array}{l}\text { items from FMI and } \\
\text { KIMS, MAAS, FFMQ } \\
\text { subscale, TMS, SMS }\end{array}$ & racial discrimination & $\begin{array}{l}\text { modified Trust } \\
\text { Game task }\end{array}$ & $\begin{array}{l}\text { short MM practice reduced discriminatory } \\
\text { behavior }\end{array}$ \\
\hline [46] & $\begin{array}{l}\text { Whitmarsh et al. } \\
\text { (2013) }\end{array}$ & 18 & - & $\mathrm{T}$ & $\begin{array}{l}\text { trait mindfulness, } \\
\text { grammar knowledge }\end{array}$ & $\begin{array}{l}\text { FFMQ, grammar's } \\
\text { bigram state transitions }\end{array}$ & $\begin{array}{l}\text { working memory } \\
\text { performance, implicit } \\
\text { classification, } \\
\text { grammatical } \\
\text { classification }\end{array}$ & $\begin{array}{l}\text { acquisition task, } \\
\text { preference task, } \\
\text { grammatical } \\
\text { classification task }\end{array}$ & $\begin{array}{l}\text { "mindfulness reduced habitual } \\
\text { responding to unconsciously } \\
\text { acquired preferences" }\end{array}$ \\
\hline [47] & $\begin{array}{l}\text { Stillman et al. } \\
\text { (2014) }\end{array}$ & $\begin{array}{l}16 \text { (study 1), } \\
18 \text { (study 2) }\end{array}$ & - & $\mathrm{T}$ & $\begin{array}{l}\text { trait mindfulness, depression, } \\
\text { cognitive assessment }\end{array}$ & MAAS, GDS, BTACT & sequence learning task & $\begin{array}{l}\text { TLT (study 1), } \\
\text { ASRT (study 2) }\end{array}$ & $\begin{array}{l}\text { "negative relationship between } \\
\text { mindfulness and implicit } \\
\text { sequence learning" }\end{array}$ \\
\hline [48] & Strick et al. (2012) & $\begin{array}{l}63 \text { (study 1), } \\
34 \text { (study 2) }\end{array}$ & Zen & $\mathrm{s}$ & - & - & $\begin{array}{l}\text { unconscious activation } \\
\text { of answers }\end{array}$ & $\begin{array}{l}\text { RAT (study 1), } \\
\text { RAT + word } \\
\text { priming (study 2) }\end{array}$ & $\begin{array}{l}\text { "20 minutes of meditation improved } \\
\text { access to the unconscious" }\end{array}$ \\
\hline
\end{tabular}

Notes: Fields of the table: reference of study inside our paper; main author and year of publication; number of subjects involved; if used, type of meditation practiced in intervention; kind of mindfulness investigated; explicit measure used; instrument for explicit measure; implicit measure used; instrument for implicit measure; result of the study. Abbreviations: ASRT, Alternating Serial Response Time Task; BDI, Beck Depression Inventory; BTACT, Brief Test of Adult Cognition by Telephone; CESD, Center of Epidemiologic Studies Depression Scale; DAS-SF1, Dysfunctional Attitude Scale-Short Form 1; FFMQ, Five Facet Mindfulness Questionnaire; FMI, Freiburg Mindfulness Inventory; GDS, Geriatric Depression Scale; IAT, Implicit Association Test; INSPIRIT, index of core spiritual experiences questionnaire; IPANAT, Implicit Positive Affect and Negative Affect Test; KIMS, Kentucky Inventory of Mindfulness Skills; Association Test; INSPIRIT, index of core spiritual experiences questionnaire; IPANAT, Implicit Positive Affect and Negative Affect Test; KIMS, Kentucky Inventory of Mindfulness Skills; Mindfulness; MM, Mindfulness Meditation; MSIT, Multi-Source Interference Task; PANAS, Positive and Negative Affect Schedule; PLOC, Perceived Locus of Causality scale; POMS, Profile of Mood Scales; PSS, Perceived Stress Scale; RAT, Remote Associates Test; RRQ, Rumination-Reflection Questionnaire; RSES, Rosenberg Self-Esteem Scale; S, State mindfulness; SCS, Self-Consciousness Scale; SDS *, Marlowe-Crowne Social Desirability Scale-Short Form C; SDS **, Self-Determination Scale; SMS, State Mindfulness Scale; STAI, State-Trait Anxiety Inventory; T, Trait mindfulness; TCI, Temperament and Character Inventory; TLT, Triplets Learning Task; TMS, Toronto Mindfulness Scale; VAS, Visual Analogue Scale. 
In their study (study 3), Brown and Ryan [33] tested whether dispositional mindfulness (measured through the Mindful Attention Awareness Scale, MAAS) was associated with greater self-awareness in relation to well-being, using the IAT to assess automatic associations between self and affective states, and a self-report test to measure the current affective state in participants. Results showed that individuals higher in mindfulness demonstrated a concordance between their implicit and explicit affective experience (see also Sauer et al. [34] for similar results). In line with these results, Koole et al. [35] showed that brief mindfulness meditation exercises increased the association between implicit and explicit self-esteem among young naïve participants. In another study, Keng et al. [36] found, in a sample of individuals with depression symptoms, that brief ( $15 \mathrm{~min}$ ) mindful acceptance training improved implicit dysfunctional attitudes related to depressed mood (assessed by IAT) in participants with high trait mindfulness. Moreover, greater levels of self-concordance between implicit and explicit dysfunctional attitudes were also observed in participants in the mindfulness versus thought wandering condition. As regards studies carried out by our research group, Crescentini et al. [37] assessed the changes in implicit and explicit self-related religious/spiritual (RS) representations in participants following an eight-week MOM program. Before and after meditation, participants were administered an implicit RS measure (IAT) and a self-report questionnaire in order to assess explicit components of personality (TCI). Relative to control condition, MOM led to congruent increases in both explicit self-transcendence (as concerns the TCI) and implicit religiosity/spirituality levels. More recently, Remmers et al. [38] showed that a short mindfulness exercise induced the down-regulation of both self-reported negative mood and implicit negative mood. Finally, by using implicit and explicit measures of autonomy and motivation, Levesque and Brown [39] found that dispositional mindfulness moderated the effect of implicit autonomy orientation on day-to-day behavioral motivation.

As concerns mindfulness and improvements of implicit attitudes, the study by Waters et al. [40] showed that mindfulness was associated with a weaker implicit self-identification with depression in a population of adult smokers. Implicit measures have also been employed in order to assess the impact of meditation on individuals' implicit attitudes toward the others; Hutcherson et al. [41] studied the effects of brief exercises $(7 \mathrm{~min}$ ) of loving-kindness meditation on both explicit and implicit positivity toward strangers, finding higher feelings of positivity toward strangers and also changes in implicit positivity toward the self. In this respect, another line of research has started to address implicit prejudices and stereotypes against members of certain stigmatized groups [31]. Recent studies that used the IAT have shown that meditation can reduce implicit bias; in particular, these studies concerned the practice of loving-kindness meditation and implicit bias toward blacks and the homeless [42,43]. Furthermore, other studies focused on mindfulness practice and reductions on implicit age and race bias and discriminatory behavior [44,45].

These studies suggest that mindfulness and loving-kindness meditation may have effects on implicit self-concepts and attitudes, as well as promoting greater levels of concordance between explicit and implicit attitudes. This suggests that mindful awareness could be involved in transforming self-evaluation and automatic or habitual reacting. However, what does it mean that meditation changes our implicit attitudes toward the others and the self, and our implicit self-representations? Can we suppose that the dimensions assessed by implicit measures refer in some way to anoetic, unconscious states?

Greenwald and Banaji [49] (p. 5) defined an implicit construct as "the introspectively unidentified (or inaccurately identified) trace of past experience that mediates responses". This definition, Hahn and Gawronski clarify [50], was originally referred to non-conscious origins of mental representations, but "it has often been interpreted in the sense that the mental representations themselves are unconscious" [50] (p. 14). Many authors have so defined as "unconscious" the attitudes and representations caught by implicit measures, and have defined as "conscious" the constructs caught by explicit measures.

Gawronski et al. [51] has considered three aspects of an attitude that the term "unconscious" can refer to: it can refer to the awareness of the origin of an attitude (source awareness), to the 
awareness of the attitude itself (content awareness), or to the awareness of the influence that an attitude has on other psychological processes (impact awareness). The authors have found that indirectly-assessed implicit attitudes indeed show unconscious characteristics, but evidence is equivocal: people can lack source awareness of indirectly assessed attitudes, but this is true also for self-reported attitudes; moreover, people seem to be aware of the attitudes assessed by indirect measures, even if these attitudes are often not consistent with self-reported evaluations, due to methodological, cognitive, or motivational factors; finally, it seems that indirectly assessed attitudes can influence other non-conscious psychological processes. Concluding, the authors argued that the term "unconscious" is used properly for indirectly assessed attitudes only with respect to impact awareness. Other studies have challenged the assumption that the IAT capture unconscious attitudes; Hahn et al. [52] asked some participants to predict their measurement scores on indirect measures; these participants were able to predict their IAT scores with a high accuracy, despite the low correlations with explicit measures. This is inconsistent with the notion that indirect measures like the IAT catch unconscious, implicit representations.

Beyond studies that have adopted the IAT as an instrument more or less able to capture implicit attitudes, other studies on mindfulness focused on implicit learning and implicit problem solving. In particular, two recent studies have shown a negative relationship between dispositional mindfulness and implicit learning and memory. Whitmarsh et al. [46] found that individuals with high dispositional mindfulness were poor learners of artificial grammar, a cognitive task employed for investigating implicit learning. The authors suggested that mindfulness reduces habitual responding to preferences that have been unconsciously acquired. Stillman et al. [47] studied the relationship between mindfulness and implicit sequence learning, a process that allows people to acquire the regularities that occur in sequences of events without intention and awareness. Their experiments showed that mindfulness and implicit sequence learning were negatively related. According to the authors, mindfulness may, therefore, impede certain cognitive functions, such as implicit sequence learning, that are at the bases of habit formation. As a consequence, mindfulness could also prevent certain maladaptive habits and addictions that depend on this type of implicit learning. Finally, a recent study using the Remote Associates Test (RAT) [48], an implicit measure of problem solving, reached the conclusion that Zen meditation improved the access to unconscious information: in two experiments it was found that Zen practitioners who meditated performed better on the RAT than Zen practitioners who did not meditate.

We may conclude that, at an anoetic level, as concern unconscious states of mind, mindfulness may affect implicit cognition and attitudes preventing some automatic and habitual reacting. A higher concordance between implicit and explicit attitudes and self-representations may reflect the greater acceptance of one's own internal states that mindfulness is believed to foster [32].

\section{Meditation and the Freudian Unconscious}

We have considered mindfulness meditation referring to implicit learning and to implicit attitudes and representations. In medical and psychological literature, the Freudian Unconscious is often discussed; thus, we will now briefly present how meditation may be related to it.

Many of Freud's views have been consistently revised in modern psychoanalysis in the confrontation with neuroscientific findings [53]. Psychoanalysis deals with the subjective life (i.e., the so called inner world) of a specific individual, its interest being turned to the Unconscious, in other words, to the psychic mechanisms below the threshold of consciousness. In particular, psychoanalysis concentrates on the dynamic unconscious (which is probably part of the semantic, episodic, and autobiographic memory, remaining inaccessible to the individual's consciousness), whereby a particular mental experience (and the emotional valence associated with it) may be kept off from consciousness by a motivational force, and actively maintained therein by inhibitory processes (the so-called—automatized—psychological defenses) [54]. 
Since the mid-1980s many articles have appeared concerning the relationship between the technique of mindfulness meditation and psychoanalytic practice (see [55]). The spontaneous observation of what happens in one's own mind (vipassana) has been associated to the practice of free association, a method adopted in psychoanalytic psychotherapy to access the unconscious, which requires a patient to say what comes into his/her consciousness without interpretation nor censorship [56,57]. As free association, mindfulness is related to the observation of the spontaneous generation of thoughts and emotions that occur inside one's own mind; those contents are observed in a detached and non-judgmental way. Freud named this attitude free-floating (or evenly-suspended) attention [58,59]: in light of today's psychoanalytic objects relation theory, the term used is role-responsiveness [60]. Due to these connections between the practice of mindfulness meditation and the method of psychoanalysis, nowadays there is a large interest in further investigating the possible synergisms between these two paths of personal transformation.

\section{Conclusions}

The aim of this study was to review studies investigating the effect of meditation and dispositional mindfulness on explicit and implicit or unconscious information processing. Few studies addressed mindfulness or meditation relating them to implicit attitudes and representations, and many of these studies employed the IAT $[33,36,37,39,40,42-44]$. Other studies that focused on implicit learning found a negative relationship between dispositional mindfulness and implicit learning and memory, thus suggesting an effect of mindfulness on implicit cognition in terms of erosion of habitual patterns of responding $[37,47,48]$. Studies suggest that more mindful individuals are less inclined to act in an automatic way; this, presumably, has repercussions both in implicit attitudes toward the others, contrasting for example stereotypes and prejudice (see [31]), and in attitudes and representations concerning the self [32].

Another key dimension of mindfulness is the capacity for self-awareness; more mindful individuals seem to be more aware and more in touch with their internal constructions and processes than less mindful individuals. As observer of their mind, meditators are engaged in explorations of their own way of making sense, suspending their verbally-labelled constructs and intellectualizations [56], and being more involved in a process of self-discovery [61] that allows them to achieve a more coherent, healthy, and authentic sense of self. In this perspective, we have noted that meditation, in particular the practice of vipassana, has been associated to the Freudian practice of "free association" which, in psychotherapy, is believed to allow access to the unconscious [56,57]. According to Sigmund Freud, and many other psychotherapists [62-64], bringing to consciousness the autonoetic components stored in the unconscious is a fundamental step of the process of psychological healing.

Solms [53] concludes that Freud considered as the most essential feature of consciousness its fundamentally dynamic nature, together with its dimension of depth (or hierarchy) in the mind. Neuroscience is, nowadays, considering the rediscovery of the embodied, emotional brain, which must be constrained by the cognitive brain, with its reality-oriented activity: thus, it is a plea for a neuroscience of the future that may become psychodynamic, integrating conscious and non-conscious, implicit and explicit, emotional and cognitive mental processes. This is especially important in therapeutic clinical situations.

In conclusion, implicit or indirect measures have proved to be interesting instruments in investigating those dimensions of the self that are barely available to our consciously-aware thinking; future experimental studies addressing this direction, as well as deeper reflections about mindfulness and consciousness, could allow a clearer understanding of the effects of meditation and mindfulness on some hidden sides of our self. 
Author Contributions: Anastasia Fabbro wrote the paper; Cristiano Crescentini helped in the preparation of the manuscript and supervised the work; Alessio Matiz contributed references and suggestions; Andrea Clarici wrote most of the contribution on meditation and the Freudian Unconscious; and Franco Fabbro supervised the work and gave fundamental suggestions for its structuring.

Conflicts of Interest: The authors declare no conflict of interest.

\section{References}

1. Tulving, E. Memory and Consciousness. Can. Psychol. 1985, 26, 1-12. [CrossRef]

2. Wheeler, M.A.; Stuss, D.T.; Tulving, E. Toward a Theory of Episodic Memory: The Frontal Lobes and Autonoetic Consciousness. Psychol. Bull. 1997, 121, 331-354. [CrossRef] [PubMed]

3. LeDoux, J. Anxious: Using the Brain to Understand and Treat Fear and Anxiety; Viking: New York, NY, USA, 2015.

4. Rosenthal, D. Higher-Order Awareness, Misrepresentation and Function. Philos. Trans. R. Soc. Lond. B Biol. Sci. 2012, 367, 1424-1438. [CrossRef] [PubMed]

5. Freud, S. The unconscious (1915). In The Standard Edition of the Complete Psychological Works of Sigmund Freud; Strachey, J., Ed.; Hogarth: London, UK, 1957; Volume 14, pp. 166-215.

6. Gombrich, R.C. What the Buddha Thought; Equinox: London, UK, 2009.

7. Gunaratana, H. Eight Mindful Steps to Happiness: Walking the Buddha's Path; Wisdom Publications: Boston, MA, USA, 2001.

8. Gunaratana, H. Mindfulness in Plain English; Wisdom Publications: Boston, MA, USA, 1991.

9. Naranjo, C.; Ornestein, R. On the Psychology of Meditation; Viking: Los Angeles, CA, USA, 1972.

10. Shapiro, D.H.; Walsh, R.N. Meditation: Classic and Contemporary Perspectives; Aldine Transaction: Chicago, IL, USA, 2008.

11. Kabat-Zinn, J. Wherever You Go, There You Are: Mindfulness Meditation in Everyday Life; Hyperion Books: New York, NY, USA, 1994.

12. Kabat-Zinn, J. Coming to Our Senses: Healing Ourselves and the World Through Mindfulness; Hyperion Books: New York, NY, USA, 2006.

13. Kabat-Zinn, J. Mindfulness-based intervention in the context: Past, present and future. Clin. Psychol. Sci. Pract. 2003, 5, 305-331. [CrossRef]

14. Ludwig, D.S.; Kabat-Zinn, J. Mindfulness in medicine. J. Am. Med. Assoc. 2008, 300, 1350-1352. [CrossRef] [PubMed]

15. Chiesa, A.; Serretti, A. A systematic review of neurobiological and clinical features of mindfulness meditations. Psychol. Med. 2010, 40, 1239-1259. [CrossRef] [PubMed]

16. Fox, K.C.; Dixon, M.L.; Nijeboer, S.; Girn, M.; Floman, J.L.; Lifshitz, M.; Ellamil, M.; Sedlmeier, P.; Christoff, K. Functional neuroanatomy of meditation: A review and meta-analysis of 78 functional neuroimaging investigations. Neurosci. Biobehav. Rev. 2016, 65, 208-228. [CrossRef] [PubMed]

17. Hasenkamp, W.; Wilson-Mendenhall, C.D.; Duncan, E.; Barsalou, L.W. Mind wandering and attention during focused meditation: A fine-grained temporal analysis of fluctuating cognitive states. Neuroimage 2012, 59, 750-760. [CrossRef] [PubMed]

18. Malinowski, P. Neural mechanisms of attentional control in mindfulness meditation. Front. Neurosci. 2013, 7, 8. [CrossRef] [PubMed]

19. Segal, Z.V.; Williams, J.M.G.; Teasdale, J.D. Mindfulness-Based Cognitive Therapy for Depression: A New Approach to Preventing Relapse; Guilford: New York, NY, USA, 2002.

20. Shapiro, S.; Carlson, L. The Art and Science of Mindfulness; American Psychological Association: Washington, DC, USA, 2009.

21. Fabbro, F.; Crescentini, C. Facing the experience of pain: A neuropsychological perspective. Phys. Life Rev. 2014, 1, 540-552. [CrossRef] [PubMed]

22. Campanella, F.; Crescentini, C.; Urgesi, C.; Fabbro, F. Mindfulness-oriented meditation improves self-related character scales in healthy individuals. Compr. Psychiatry 2014, 55, 1269-1278. [CrossRef] [PubMed]

23. Cloninger, C.R. A systematic method for clinical description and classification of personality variants: A proposal. Arch. Gen. Psychiatry 1987, 44, 573-588. [CrossRef] [PubMed]

24. Crescentini, C.; Matiz, A.; Fabbro, F. Improving personality/character traits in individuals with alcohol dependence: The influence of mindfulness-oriented meditation. J. Addict. Dis. 2015, 34, 75-87. [CrossRef] [PubMed] 
25. Gawronki, B.; Bodenhausen, G.V. Associative and propositional processes in evaluation: An integrative review of implicit and explicit attitude change. Psychol. Bull. 2006, 132, 692-731. [CrossRef] [PubMed]

26. Greenwald, A.G.; McGhee, D.E.; Schwartz, J.L. Measuring individual differences in implicit cognition: The implicit association test. J. Pers. Soc. Psychol. 1998, 74, 1464-1480. [CrossRef] [PubMed]

27. Crescentini, C.; Aglioti, S.; Fabbro, F.; Urgesi, C. Virtual lesions of the inferior parietal cortex induce fast changes of implicit religiousness/spirituality. Cortex 2014, 54, 1-15. [CrossRef] [PubMed]

28. Crescentini, C.; di Bucchianico, M.; Fabbro, F.; Urgesi, C. Excitatory stimulation of the right inferior parietal cortex lessens implicit religiousness/spirituality. Neuropsychologia 2015, 70, 71-79. [CrossRef] [PubMed]

29. Zeigler-Hill, V.; Terry, C. Perfectionism and explicit self-esteem: The moderating role of implicit self-esteem. Self Identity 2007, 6, 137-153. [CrossRef]

30. Bosson, J.K.; Brown, R.P.; Zeigler-Hill, V.; Swann, W.B., Jr. Self enhancement tendencies among people with high explicit self-esteem: The moderating role of implicit self-esteem. Self Identity 2003, 2, 169-187. [CrossRef]

31. Burgess, D.J.; Beach, M.C.; Saha, S. Mindfulness practice: A promising approach to reducing the effects of clinician implicit bias on patients. Patient Educ. Couns. 2017, 100, 372-376. [CrossRef] [PubMed]

32. Crescentini, C.; Capurso, V. Mindfulness meditation and explicit and implicit indicators of personality and self-concept changes. Front. Psychol. 2015, 6, 44. [CrossRef] [PubMed]

33. Brown, K.W.; Ryan, R.M. The benefits of being present: Mindfulness and its role in psychological well-being. J. Pers. Soc. Psychol. 2003, 84, 822-848. [CrossRef] [PubMed]

34. Sauer, S.; Walach, H.; Schmidt, S.; Hinterberger, T.; Horan, M.; Kohls, N. Implicit and explicit emotional behavior and mindfulness. Conscious. Cogn. 2011, 20, 1558-1569. [CrossRef] [PubMed]

35. Koole, S.L.; Govorun, O.; Cheng, C.M.; Gallucci, M. Pulling yourself together: Meditation promotes the congruence between implicit and explicit self-esteem. J. Exp. Soc. Psychol. 2009, 45, 1220-1226. [CrossRef]

36. Keng, S.L.; Seah, S.T.H.; Tong, E.M.W.; Smoski, M. Effects of brief mindful acceptance induction on implicit dysfunctional attitudes and concordance between implicit and explicit dysfunctional attitudes. Behav. Res. Ther. 2016, 83, 1-10. [CrossRef] [PubMed]

37. Crescentini, C.; Urgesi, C.; Campanella, F.; Eleopra, R.; Fabbro, F. Effects of an 8-week meditation program on the implicit and explicit attitudes toward religious/spiritual self-representations. Conscious. Cogn. 2014, 30, 266-280. [CrossRef] [PubMed]

38. Remmers, C.; Topolinski, S.; Koole, S.L. Why being mindful may have more benefits than you realize: Mindfulness improves both explicit and implicit mood regulation. Mindfulness 2016, 7, 829-837. [CrossRef]

39. Levesque, C.; Brown, K.V. Mindfulness as a moderator of the effect of implicit motivational self-concept on day-to-day behavioral motivation. Motiv. Emot. 2007, 31, 284-299. [CrossRef]

40. Waters, A.J.; Reitzel, L.R.; Cinciripini, P.; Li, Y.; Marcus, M.T.; Vidrine, J.I.; Wetter, D.W. Associations Between Mindfulness and Implicit Cognition and Self-Reported Affect. Subst. Abus. 2009, 30, 328-332. [CrossRef] [PubMed]

41. Hutcherson, C.A.; Seppala, E.M.; Gross, J.J. Loving-kindness meditation increases social connectedness. Emotion 2008, 8, 720-724. [CrossRef] [PubMed]

42. Kang, Y.; Gray, J.R.; Dovidio, J.F. The nondiscriminating heart: Lovingkindness meditation training decreases implicit intergroup bias. J. Exp. Psychol. Gen. 2014, 143, 1306-1313. [CrossRef] [PubMed]

43. Stell, A.J.; Farsides, T. Brief loving-kindness meditation reduces racial bias, mediated by positive other-regarding emotions. Motiv. Emot. 2016, 40, 140-147. [CrossRef]

44. Lueke, A.; Gibson, B. Mindfulness meditation reduces implicit age and race bias: The role of reduced automaticity of responding. Soc. Psychol. Pers. Sci. 2014. [CrossRef]

45. Hahn, A.; Judd, C.M.; Hirsh, H.K.; Blair, I.V. Awareness of implicit attitudes. J. Exp. Psychol. Gen. 2014, 143, 1369-1392. [CrossRef] [PubMed]

46. Whitmarsh, S.; Uddén, J.; Barendregt, H.; Petersson, K.M. Mindfulness reduces habitual responding based on implicit knowledge: Evidence from artificial grammar learning. Conscious. Cogn. 2013, 22, 833-845. [CrossRef] [PubMed]

47. Stillman, C.M.; Feldman, H.; Wambach, C.G.; Howard, J.H.; Howard, D.V. Dispositional mindfulness is associated with reduced implicit learning. Conscious. Cogn. 2014, 28, 141-150. [CrossRef] [PubMed]

48. Lueke, A.; Gibson, B. Brief mindfulness meditation reduces discrimination. Psychol. Conscious. Theor. Res. Pract. 2016, 3, 34-44. [CrossRef] 
49. Greenwald, A.G.; Banaji, M.R. Implicit social cognition: Attitudes, self-esteem, and stereotypes. Psychol. Rev. 1995, 102, 4-27. [CrossRef] [PubMed]

50. Hahn, A.; Gawronski, B. Implicit social cognition. In The Stevens' Handbook of Experimental Psychology and Cognitive Neuroscience, 4th ed.; Wixted, J.T., Ed.; Wiley: Malden, MA, USA, 2016.

51. Gawronski, B.; Hofmann, W.; Wilbur, C. Are 'implicit' attitudes unconscious? Conscious. Cogn. 2006, 15, 485-499. [CrossRef] [PubMed]

52. Strick, M.; van Noorden, T.H.; Ritskes, R.R.; de Ruiter, J.R.; Dijksterhuis, A. Zen meditation and access to information in the unconscious. Conscious. Cogn. 2012, 21, 1476-1481. [CrossRef] [PubMed]

53. Solms, M. The Conscious Id. Neuropsychoanalysis 2013, 15, 5-19. [CrossRef]

54. Freud, S. (1920) Beyond the Pleasure Principle. In The Standard Edition of the Complete Psychological Works of Sigmund Freud; Strachey, J., Ed.; Hogarth: London, UK, 1955; Volume 18, pp. 7-64.

55. Cooper, P. Zen meditation, reverie, and psychoanalytic listening. Psychoanal. Rev. 2014, 101, $795-813$. [CrossRef] [PubMed]

56. Delmonte, M.M. Meditation and the Unconscious. J. Contemp. Psychoter. 1995, 25, 223-242. [CrossRef]

57. Hirst, I.S. Perspectives of mindfulness. J. Psychiatr. Ment. Health Nurs. 2003, 10, 359-366. [CrossRef] [PubMed]

58. Freud, S. Recommendations to physicians practising psycho-analysis (1912). In The Standard Edition of the Complete Psychological Works of Sigmund Freud; Strachey, J., Ed.; Hogarth: London, UK, 1958; Volume 12, pp. 111-116.

59. Horney, K. Final Lectures; Ingram, D., Ed.; Norton: New York, NY, USA, 1987.

60. Sandler, J. Countertransference and role-responsiveness. Int. Rev. Psycho-Anal. 1976, 3, $43-47$.

61. Welwood, J. Meditation and the Unconscious: A new perspective. J. Transpers. Psychol. 1977, 9, 1-26.

62. Gay, P. Freud: A Life for Our Time; W. W. Norton: New York, NY, USA, 1988.

63. Horney, K. Neurosis and Human Growth. The Struggle toward Self-Realization; Norton: New York, NY, USA, 1950.

64. Germer, C.K.; Siegel, R.D.; Fulton, P.R. (Eds.) Mindfulness and Psychotherapy; Guilford Press: New York, NY, USA, 2005.

(C) 2017 by the authors. Licensee MDPI, Basel, Switzerland. This article is an open access article distributed under the terms and conditions of the Creative Commons Attribution (CC BY) license (http:/ / creativecommons.org/licenses/by/4.0/). 